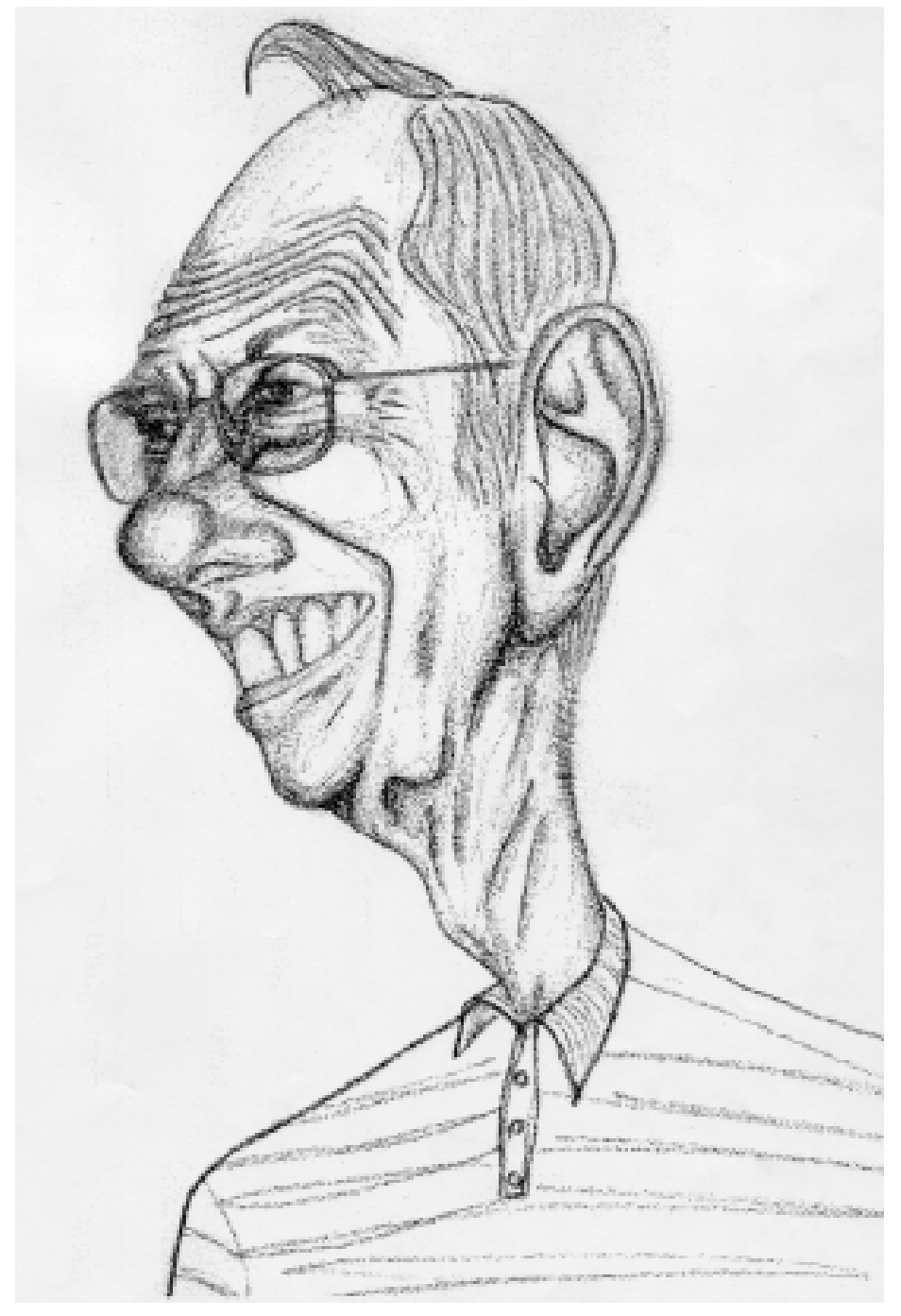

John Schmitz por Camilo Kolimi Veiga D'Angelis 


\section{Quem é o nosso homenageado}

Um dos pioneiros na implantação da pesquisa em Lingüística Aplicada no início da década de setenta no Brasil, o Prof. John Robert Schmitz é americano, da cidade de Nova York, tendo se instalado no país em 1970 e se naturalizado brasileiro em 1993. Seu interesse pelo Brasil e pela língua portuguesa, porém, data da época do mestrado em ensino de espanhol e inglês como línguas estrangeiras pelo Teachers College, da Universidade de Columbia (1959-1961), quando decidiu aprender português. Nessa época já era graduado em língua e literatura espanholas pelo Brooklyn College, de Nova York, já havia tido contato com a literatura e cultura hispano-americanas e já atuara como professor de espanhol em escolas públicas de $2^{\circ}$. grau do Estado de Nova Jersey.

Veio ao Brasil pela primeira vez em 1961, graças a uma bolsa Fullbright para um ano de estudo e pesquisa na área de língua, literatura e cultura brasileiras junto à Universidade de São Paulo (USP). O assunto de sua pesquisa e de sua primeira publicação brasileira (1966) foi a obra Os Sertões, de Euclides da Cunha. E foi em função dela que se deram suas andanças nessa primeira passagem pelo país. Esteve em São José do Rio Pardo, interior de São Paulo, onde Euclides escreveu parte de sua obra. Lá participou da Semana Euclideana de 1961 e conheceu D. Maria Lúcia B. de Oliveira, com quem se casaria em 1963, nos EUA. Esteve também em Canudos e no Instituto de Geografia e História de Salvador, estudando o conflito retratado por Euclides da Cunha.

Já nessa primeira visita ao Brasil, teve a oportunidade de conhecer outras obras e autores de interesse para o estudo da língua, da cultura e da história brasileiras. Além da literatura (Graciliano Ramos, José Lins do Rego, Machado de Assis), da sociologia (Gilberto Freire) e da história (Rocha Pombo, Hélio Viana), debruçou-se sobre dicionários e gramáticas do português brasileiro e livros didáticos de língua e filologia portuguesas. A perspectiva lingüística de estudo da língua brasileira só seria conhecida mais tarde, quando de sua segunda vinda ao Brasil, através das contribuições de Mattoso Câmara.

E quando voltou a São Paulo, em 1965, o Prof. John teve também a oportunidade de conhecer as iniciativas pioneiras do Prof. Gomes de Mattos no campo da Lingüística Aplicada ao Ensino de Línguas. O Prof. Gomes de Matos assim relata o episódio: 
John Schmitz and I first met in July 1965 during the Primeiro Seminário Brasileiro de Orientação Lingüistica para Professores, which tookplace in Rio de Janeiro. He had just arrived from the U.S. and wanted to know about Applied Linguistics in Brazil. We chatted after my talk and be told me he would be making this country his new bome. From then on, Jobn and I have kept in touch, more intensely so during my stay in São Paulo, from 1966 through 1979, when I directed the Centro de Lingüistica Aplicada Yázigi. "O amigo John", as I refer to bim, when telling students about that American who became a Brazilian citizen, shared an interest in Creativity, which led me to ask him to contribute to the pioneering Newsletter Creativity - New Ideas in Language Teaching, published by CLA-Yázigi/SP. He complied with a fine article on "Humanizing the teaching of grammar in language teaching" (No.19, July, 1976, pp.1-5), in which there is a section devoted to Creative approaches to humanizing the teaching of Grammar. (...) In short, John is one of our pioneers in doing Applied Creative Linguistics and in fostering creative approaches to language teaching and learning (commendably be has been active in Applied Linguistics in Language Education, through a dual interest in belping educate teachers of English and Portuguese). ${ }^{1}$

Quando, em 1970, aceitou o convite para o cargo de professor visitante junto à Faculdade de Filosofia, Ciências e Letras de São José do Rio Pardo e instalou-se definitivamente no Brasil, o Prof. John já havia iniciado um curso de doutoramento no Teachers College da Universidade de Columbia e há sete anos atuava como Assistant Professor de espanhol e de metodologia de ensino de línguas estrangeiras no Southern Connecticut State College (atualmente Southern Connecticut State University), órgão da rede pública de ensino superior do Estado americano de Connecticut.

Em 1971 foi contratado pela Pontifícia Universidade Católica de São Paulo (PUC-SP) para atuar no Programa de Pós-graduação em Lingüística Aplicada ao Ensino de Línguas. Logo no ano seguinte, juntamente com as Profas. Mary Kato e Leila Bárbara, então professoras do mesmo Programa, ministrou um dos primeiros cursos de Lingüística (Sintaxe) do Programa de Mestrado em Lingüística da Universidade Estadual de Campinas (UNICAMP). Doutourou-se pela PUC-SP em 1975

\footnotetext{
${ }^{1}$ Gomes de Mattos, F. Session on Creativity and Peaceful Communication: A Brazilian Experience. WinterFest of the Creative Education Foundation. San Diego, February 6, 2004, inédito.
} 
com a tese: "A ocorrência de ser e estar em orações predicativas e o ensino de português para falantes de inglês" e, em 1978, obteve o título de professor titular pela mesma universidade. Ao longo desse período, desenvolveu atividades de ensino, pesquisa e extensão no campo da descrição e ensino de línguas, sobretudo do inglês como LE.

Em 1988, foi contratado pela UNICAMP para atuar no Departamento de Lingüística Aplicada e no Programa de pós-graduação em Lingüística Aplicada do Instituto de Estudos da Linguagem (IEL). Anteriormente à sua ida para Campinas, havia colaborado como professor visitante em outras universidades do interior paulista: Programa de Mestrado em Semiótica e Lingüística da Universidade Metodista de Piracicaba (UNIMEP) em 1977-80; Programa de Mestrado em Lingüística da Universidade de Mogi das Cruzes em 1978-79; Departamento de Lingüística da Universidade Estadual Paulista (UNESP) de Assis em 1987-88.

Aposentou-se pela UNICAMP em 2003, depois de ter sido aprovado em concurso público para professor titular em Ensino/aprendizagem de LE em 1998 e ter atuado tanto no ensino quanto na pesquisa e em atividades de extensão, notadamente no campo da Lingüística Aplicada ao Ensino de Línguas e de Tradução, mas também no campo da Lexicologia, Lexicografia e Gramática do português.

Ao longo de sua trajetória no Brasil, o Prof. John teve um papel importante na formação de um grande número de lingüistas, lingüistas aplicados e professores de língua que hoje atuam com destaque na docência e pesquisa em diferentes instituições do país. Orgulha-se também de ter contribuído para a consolidação do campo teórico e aplicado dos estudos da linguagem através da participação não só em programas de pós-graduação como também em publicações e eventos científicos nacionais e internacionais, associações e grupos de trabalho, além das 235 bancas, tanto de dissertações e teses quanto de concursos para professores, de que participou ao longo desse período nas mais diversas instituições de diferentes pontos do país.

Todos os que tiveram a oportunidade de conviver com o Prof. John ao longo desses anos reconhecem seu estilo parcimonioso, sua solicitude discreta e bem humorada, seu apreço pela língua portuguesa. A esse respeito, ele disse uma vez o seguinte: 
Graças ao tempo investido no estudo, os meus alunos e os colegas dizem que tenho um bom vocabulário. Em certos momentos, usei certas palavras que os meus alunos não sabiam. Alguns exemplos são: "escarafunchar", "açodamento", "miríade" e "emular". Não é a minha intenção humilhar ninguém. Creio que o professor precisa dar um bom exemplo e, no meu caso, na qualidade de "ex-estrangeiro", é uma questão de respeito ao idioma. É preciso mostrar que o idioma é rico e expressivo (SCHMITZ, 2002).

Apesar de pouco afeito ao jogos de guerra do meio acadêmico, não perdeu a oportunidade de cerrar fileiras e investir publicamente contra a iniciativa e os argumentos do autor da conhecida lei contra o uso de estrangeirismos no país. Foi quando não hesitou em deixar de lado o tom habitual e os argumentos propriamente lingüísticos, ou "científicos", para cobrar do deputado um outro tipo de compromisso:

O problema é outro. O que desnacionaliza é a venda por preços irrisórios de empresas brasileiras em boa situação financeira aos interesses estrangeiros, o que desfigura a nação é a desonestidade, a impunidade, e a diferença de poder aquisitivo entre as classes sociais, o que coloniza é a submissão às determinações dos fundos e agências internacionais. Muito mais do que o idioma, os professores de português nas escolas do ensino fundamental e médio devem ser defendidos. O que realmente deve ser defendido é o salário, as condições do ensino com a possibilidade de bolsas de estudo para uma formação continuada dos mesmos durante a carreira, enfim, a necessária "desproletarização" do professor (SCHMITZ, 2001).

Mas é sobretudo na qualidade de colecionador de palavras raras (quem não se lembra de vê-lo sempre "assoberbado", por exemplo?) e de observador atento dos usos da língua e dos estados de alma que neles são velados e desvelados, que o Prof. John não nos tem deixado esquecer de que foi pelas mãos de Euclides da Cunha que aportou por aqui.

Inês Signorini Campinas, maio de 2004. 